\title{
CONVERSION OF AMMONIUM POLYPHOSPHATE (APP) IN ACIDIC SOIL AND ITS EFFECT ON SOIL PHOSPHORUS AVAILABILITY
}

\author{
CHEN, Y. L. ${ }^{1 \#}-$ CHEN, X. J. ${ }^{1 \#}-$ ZHANG, C. L. ${ }^{1}-$ TU, P. F. ${ }^{1,2}-$ DENG, L. S. ${ }^{1 *}$ \\ ${ }^{1}$ Department of Plant Nutrition, College of Resources and Environment, South China \\ Agricultural University, 510642 Guangzhou, PR China \\ ${ }^{2}$ Dongguan Yixiang Liquid Fertilizer Co., Ltd, 523125 Dongguan, PR China \\ ${ }^{\#}$ These authors have contributed equally to this work \\ *Corresponding author \\ e-mail: lshdeng@scau.edu.cn
}

(Received 10 $0^{\text {th }}$ Dec 2019; accepted 6 ${ }^{\text {th }}$ May 2020)

\begin{abstract}
To clarify the transformation of ammonium polyphosphate (APP) in acidic soil and its effect on soil phosphorus availability is prerequisite for the rational application of APP with different degrees of polymerization. The present study used industrial-grade monoammonium phosphate (MAP) as control, lateritic red soil and latosol were used as test soils, the soil culture experiments were conducted for 50 days. The effects of different fertilization treatments on soil availability and transformation of inorganic phosphorus forms in lateritic red soil and latosol were compared between three kinds of APP (APP1, APP2, APP3) with different degree of aggregation and APP3 with MAP (A3:M). Among them, APP1 (15-62-0) is ammonium polyphosphate mainly composed of low and middle polymer; APP2 (2043-0) is ammonium polyphosphate mainly composed of middle and high polymer; and APP3 (13-70-0) is evenly distributed. The results showed that (1) in lateritic red soil, the effect of APP1 alone was the best, while in latosol, the effect of A3:M on improving soil available phosphorus content was remarkable; (2) the available phosphorus content in lateritic red soil under fertilizer treatment was much higher than that in latosol; (3) the content of inorganic phosphorus in the two soil types were O-P > Fe-P > Al-P > Ca-P.

Keywords: slow release phosphate fertilizer, degree of polymerization composition, forms of phosphorus, transformation of inorganic phosphorus, soil culture, Olsen-P
\end{abstract}

\section{Introduction}

As one of the essential nutrient elements in plant growth and development, phosphorus $(\mathrm{P})$ is an important component of nucleic acids, nucleoproteins, phospholipids and adenine nucleoside triphosphate (ATP) while playing a vital role for plants. Numerous studies showed the significant effect of the application of $\mathrm{P}$ fertilizer on promoting crop growth and increasing yield. For example, an early study showed that the different $\mathrm{P}$ fertilizer affected the yield of herbage differently in the growing season (Sheil et al., 2016). The study of Rosen et al. (2014) revealed that appropriate phosphorus application is the key to optimizing tuber yield, solid content, nutritional quality and disease resistance of potato (Solanum tuberosum L.). Furthermore, Singh et al. (2014) demonstrated that phosphorus deficiency would reduce leaf area and thus affects the photosynthesis, which ultimately affects growth and development of soybean (Glycine max (Linn.) Merr.). Normally, phosphorus absorbed by plants is composed of organic phosphorus and inorganic phosphorus, mainly inorganic phosphorus. From inorganic phosphorus, orthophosphate is the main form of plant uptake; plants can also absorb pyrophosphate and metaphosphate, and quickly hydrolyze into orthophosphate, 
which is used by plants. Orthophosphates absorbed by plants from the soil are mainly $\mathrm{H}_{2} \mathrm{PO}_{4}{ }^{-}$and $\mathrm{HPO}_{4}{ }^{2-}$ whilst $\mathrm{PO}_{4}{ }^{3-}$ is not suitable for plants to absorb (de Oliveira Araújo et al., 2012).

The main forms of phosphorus in soil are inorganic phosphorus. Soil types, crop rhizosphere, crop cultivation methods, types and amounts of phosphorus fertilizer have different effects on soil phosphorus transformation (Giles et al., 2015). Moreover, $\mathrm{pH}$, species of soil ions, aeration, temperature and water are also important factors affecting plant phosphorus uptake, among which $\mathrm{pH}$ is the most important one (Smith et al., 2011). In recent years, as a new type of phosphate fertilizer with high nutrient concentration, ammonium polyphosphate (APP) has gradually come into the public's view and is a compound with different degree of polymerization (n) (Yang et al., 2019). As a new type of phosphate fertilizer, agricultural ammonium polyphosphate has many advantages. For example, the solubility of short-chain ammonium polyphosphate is higher than that of ordinary phosphate fertilizer, which can increase the content of phosphorus in liquid fertilizer (Do Nascimento et al., 2018). The study of Summerhays et al. (2017) indicated polyphosphate is not directly absorbed by plants, but is gradually hydrolyzed into orthophosphate in soil and used by plants, so it is a slow-soluble and long-term phosphorus fertilizer.

Although short-chain ammonium polyphosphate has a series of advantages, its application effect is closely related to soil texture type, soil $\mathrm{pH}$, soil ion composition, temperature and soil biological characteristics. At present, there are few reports on the transformation and availability of phosphorus forms of ammonium polyphosphate in highly acidic soils. Thus, different degree of polymerization (APP) was used to carry out soil culture experiments in present study in order to explore the effects of different degree of polymerization (APP) on the forms and availability of phosphorus in acidic soils.

\section{Materials and methods}

\section{Test soil}

Present study was conducted in College of resources and environment, South China Agricultural University, Guangzhou, Guangdong Province, China. The tested soil were latosol and lateritic red soil, and the physicochemical properties of the tested soil were shown in Table 1. Among them, $\mathrm{pH}$ was measured by $\mathrm{pH}$ meter (PHS-3G, INESA Scientific Instrument Co., Ltd, Shanghai). EC was measured by salinometer (SX-650, Shanghai San-Xin Instrument, Shanghai). Soil organic matter was measured by potassium dichromate-volumetric method (external heating method) (Shaw, 1959). Soil available phosphorus was extracted with $\mathrm{NH}_{4} \mathrm{~F}-\mathrm{HCl}$, and determined with ultraviolet visible spectrophotometer (UV-5100B, Shanghai Metash Instruments Co., Ltd, Shanghai) at $\lambda=700 \mathrm{~nm}$ by molybdenum antimony anti colorimetry (Lu, 1999). Soil available iron was extracted with DTPA solution and measured by atomic absorption spectrophotometer (SP-3530AA, Shanghai Chenqiao Biosciences Co., Ltd, Shanghai) (Lu, 1999). Soil exchangeable calcium was also measured by atomic absorption spectrophotometer (SP-3530AA, Shanghai Chenqiao Biosciences Co., Ltd, Shanghai) (Martin and Reeve, 1955).

It could be seen from Table 1 that the acidity of latosol was stronger than that lateritic red soil. The content of organic matter, available iron and exchangeable calcium in latosol was higher than that in lateritic red soil, but the content of available 
phosphorus in both soil types were $1.6 \mathrm{mg} \cdot \mathrm{kg}^{-1}$, less than $5.0 \mathrm{mg} \cdot \mathrm{kg}^{-1}$, so they were all serious phosphorus deficient soils, which could eliminate the interference of phosphorus in the soil. It was found that the two kinds of soil can be rubbed into $3 \mathrm{~mm}$ thin strips after being fully moistened with water and evenly mixed, but they were easy to break when bending, so they were medium loam.

Table 1. The physicochemical properties of the tested soil

\begin{tabular}{c|c|c|c|c|c|c}
\hline Soil type & $\mathbf{p H}$ & $\begin{array}{c}\mathbf{E C} \\
\left(\boldsymbol{\mu} \mathbf{S} \cdot \mathbf{c m}^{-1}\right)\end{array}$ & $\begin{array}{c}\text { Organic matter } \\
\left(\mathbf{g} \cdot \mathbf{k g}^{-1}\right)\end{array}$ & $\begin{array}{c}\text { Available } \\
\mathbf{p h o s p h o r u s ~}\left(\mathbf{m g} \cdot \mathbf{k g}^{-1}\right)\end{array}$ & $\begin{array}{c}\text { Available iron } \\
\left(\mathbf{m g} \cdot \mathbf{k g}^{-1}\right)\end{array}$ & $\begin{array}{c}\text { Exchangeable } \\
\mathbf{c a l c i u m}\left(\mathbf{m g} \cdot \mathbf{k g}^{-1}\right)\end{array}$ \\
\hline Lateritic red soil & $5.72 \pm 0.05 \mathrm{a}$ & $200.0 \pm 0.02 \mathrm{a}$ & $3.4 \pm 0.32 \mathrm{~b}$ & $1.6 \pm 0.18 \mathrm{a}$ & $1.3 \pm 0.22 \mathrm{~b}$ & $644.0 \pm 28.6 \mathrm{~b}$ \\
Latosol & $4.98 \pm 0.03 \mathrm{~b}$ & $68.0 \pm 0.03 \mathrm{~b}$ & $13.6 \pm 0.58 \mathrm{a}$ & $1.6 \pm 0.15 \mathrm{a}$ & $7.0 \pm 0.40 \mathrm{a}$ & $820.0 \pm 15.9 \mathrm{a}$ \\
\hline
\end{tabular}

\section{Test fertilizer}

Taking industrial grade monoammonium phosphate (MAP) as control, solid APP was the test fertilizer, ammonium sulfate $\left(\left(\mathrm{NH}_{4}\right)_{2} \mathrm{SO}_{4}, 21-0-0\right)$ was used to make up for the lack of nitrogen. Solid APP was provided by the College of chemical engineering of Sichuan University, which was called APP1, APP2 and APP3 for short. The main polymerization degree of APP1 (15-62-0) is middle low polymer (oligomer: middle polymer: high polymer $=73 \%: 27 \%: 0.2 \%$ ); the main polymerization degree of APP2 (20-43-0) is middle high polymer (oligomer: middle polymer: high polymer $=4 \%: 76 \%$ : $20 \%$ ); the polymerization degree of APP3 (13-70-0) is evenly distributed (oligomer: middle polymer: high polymer $=23 \%: 43 \%: 34 \%$ ). (see Table 2 for the specific aggregation degree distribution of APP).

Table 2. Composition distribution of APP polymerized salt

\begin{tabular}{c|c|c|c}
\hline \multirow{2}{*}{ Phosphate species } & \multicolumn{3}{|c}{$\mathbf{P}_{\mathbf{2}} \mathbf{O}_{\mathbf{5}} \%$} \\
\cline { 2 - 4 } & APP1 & APP2 & APP3 \\
\hline Orthophosphate & 9.79 & 0.49 & 4.95 \\
Pyrophosphate & 35.50 & 1.39 & 11.39 \\
Tripolyphosphate & 13.11 & 10.18 & 10.05 \\
Tetrapolyphosphate & 3.67 & 22.59 & 19.88 \\
Pentapolyphosphate & 0.09 & 6.34 & 7.27 \\
Polyphosphate & 0.05 & 2.64 & 16.80 \\
Total phosphorus & 43.76 & 43.50 & 60.00 \\
\hline
\end{tabular}

In this experiment, orthophosphoric acid and pyrophosphoric acid were set as oligomer, tripolyphosphate and tetrachlorophosphoric acid as medium polymer, and pentamer or more as high polymer.

\section{Experimental details}

In this experiment, MAP, APP1, APP2, APP3, APP3: MAP $\left(\mathrm{P}_{2} \mathrm{O}_{5}\right.$ mass ratio 2:1, $\mathrm{A} 3: \mathrm{M}$ in the following text) and $\mathrm{CK}$ (no phosphorus) were respectively set on the latosol and lateritic red soil. The phosphorus application amount was $\mathrm{P}_{2} \mathrm{O}_{5}: 0.1 \mathrm{~g}$ (equal 
phosphorus and other nitrogen, and supplement the insufficient nitrogen with $\left(\mathrm{NH}_{4}\right)_{2} \mathrm{SO}_{4}$, as shown in Table 3). Take a $2 \mathrm{~mm}$ air dried soil sample and put it into a plastic cup (the cup height was $6.6 \mathrm{~cm}$, the cup mouth diameter was $6.4 \mathrm{~cm}$, and the cup bottom diameter was $4.0 \mathrm{~cm}$ ). After fully mixing the said fertilizer with $100 \mathrm{~g}$ soil, spray the same amount of water evenly on the soil surface, and put it in a constant temperature and humidity incubator (LHS-250HC- I, Shanghai Bluepard Instruments Co., Ltd., Shanghai) with a temperature of $25{ }^{\circ} \mathrm{C}$ and a humidity of $80 \%$. During this period, the soil moisture content was kept at $60-65 \%$ of the field water capacity by weighing method. Soil samples were taken at 5, 10, 15, 30, and 50 days of culture respectively, five times at a time. The samples were dried and screened for $2 \mathrm{~mm}$. And then, the contents of Al-P, Fe-P, O-P, Ca-P and Olsen-P in soil were determined respectively.

Table 3. Fertilization amount of each fertilization treatment on two kinds of soil $\left(\mathrm{g} \cdot 100 \mathrm{~g}^{-1}\right.$ soil)

\begin{tabular}{c|c|c|c|c}
\hline Treatments & APP & MAP & $\mathbf{( N H}_{\mathbf{4}} \mathbf{2}_{\mathbf{2}} \mathbf{S O}_{\mathbf{4}}$ & $\begin{array}{c}\text { Nitrogen from } \\
\text { phosphate fertilizer }\end{array}$ \\
\hline APP1 & 0.230 & - & 0.066 & 0.032 \\
APP2 & 0.230 & - & - & 0.046 \\
APP3 & 0.170 & - & 0.114 & 0.022 \\
APP3:MAP (2:1) & 0.111 & 0.023 & 0.138 & 0.017 \\
MAP & - & 0.160 & 0.124 & 0.020 \\
CK & - & - & 0.218 & - \\
\hline
\end{tabular}

\section{Grading determination of inorganic phosphorus forms in acid soil}

The inorganic phosphorus in acid soil was classified into four grades: Al-P, Fe-P, O$\mathrm{P}$ and Ca-P (Chang and Jackson, 1957). Refer to soil agrochemical analysis Soil agrochemical analysis ( $\mathrm{Lu}, 1999)$, the inorganic phosphorus in acid soil was extracted by $\quad 1 \mathrm{~mol} \cdot \mathrm{L}^{-1} \quad \mathrm{NH}_{4} \mathrm{Cl}, \quad 0.5 \mathrm{~mol} \cdot \mathrm{L}^{-1} \quad \mathrm{NH}_{4} \mathrm{~F}, \quad 0.1 \mathrm{~mol} \cdot \mathrm{L}^{-1} \mathrm{NaOH}, \quad 0.3 \mathrm{~mol} \cdot \mathrm{L}^{-1}$ $\mathrm{Na}_{3} \mathrm{C}_{6} \mathrm{H}_{5} \mathrm{O}_{7} \cdot 2 \mathrm{H}_{2} \mathrm{O}, \mathrm{Na}_{2} \mathrm{~S}_{2} \mathrm{O}_{4}$ and $0.5 \mathrm{~mol} \cdot \mathrm{L}^{-1} \mathrm{H}_{2} \mathrm{SO}_{4}$, and determined with ultraviolet visible spectrophotometer (UV-5100B, Shanghai Metash Instruments Co., Ltd, Shanghai) at $\lambda=700 \mathrm{~nm}$ by molybdenum antimony anti colorimetry.

\section{Determination of available phosphorus in acid soil}

Refer to soil agrochemical analysis (Lu, 1999), the content of available phosphorus in soil was extracted with $\mathrm{NH}_{4} \mathrm{~F}-\mathrm{HCl}$, and determined with ultraviolet visible spectrophotometer (UV-5100B, Shanghai Metash Instruments Co., Ltd, Shanghai) at $\lambda=700 \mathrm{~nm}$ by molybdenum antimony anti colorimetry.

\section{Statistical analyses}

This study was managed as a split block design. Data were analyzed using statistical software 'Statistix 8.1' (Analytical Software, Tallahassee, FL, USA) while differences among means were separated by using least significant difference (LSD) test at 5\% probability level. 'Sigma Plot 14.0 ' was used for graphical representation. 


\section{Results}

\section{Available P content in soil}

As shown in Figure 1, soil available P content was significantly affected by different phosphorus source treatments in different periods. For lateritic red soil, the highest available P content were recorded in APP1 in whole cultured time. There was no significant difference between MAP and APP3 at 15, 30 and 50 days after the fertilization while lower available P content was recorded in A3:M than MAP in whole cultured time. For latosol, the highest available P content was recorded in APP1 at both 5 and 10 days after fertilization whilst at 15, 30 and 50 days after fertilization the highest content was all recorded in A3:M. Both APP3 and A3:M had higher available P content than MAP at 15, 30 and 50 days after fertilization.
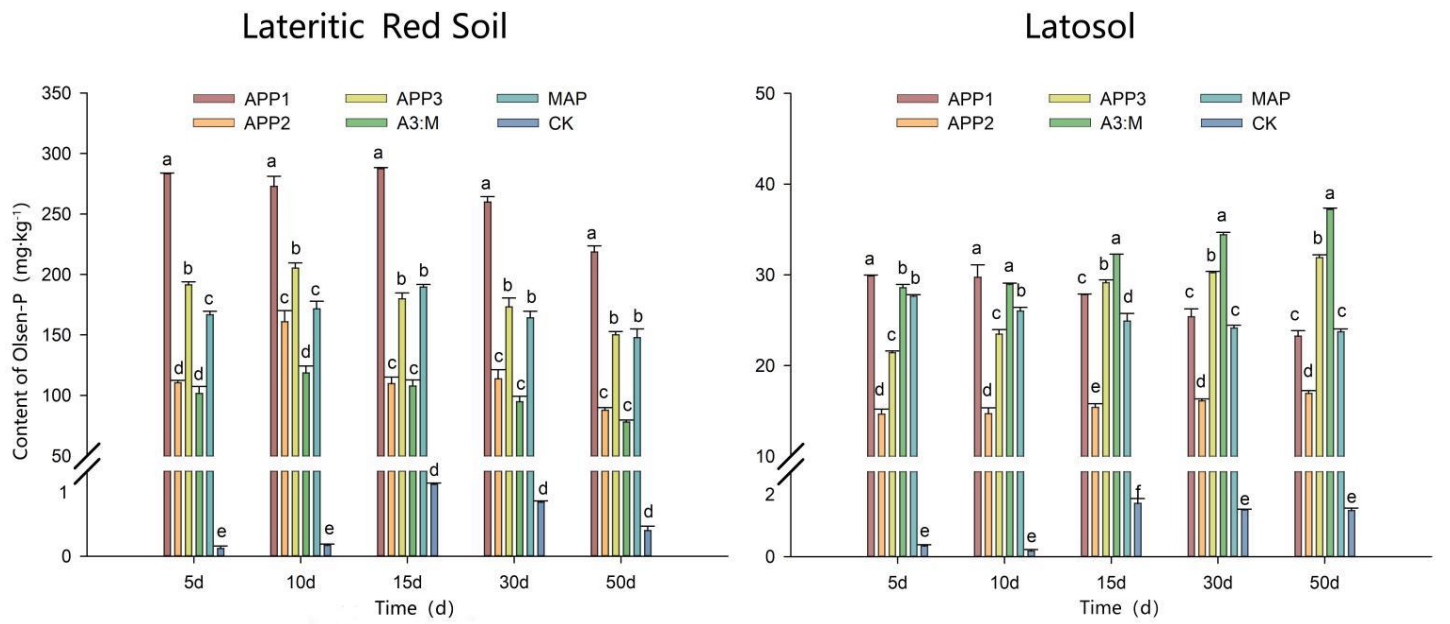

Figure 1. Effects of different treatments on soil availability of lateritic red soil and latosol. (Capped bars represent $S$. E. of three replicates. Means sharing a common letter do not differ significantly at $(P \leq 0.05)$ according to least significant difference $(L S D)$ test)

\section{Al-P content in soil}

As shown in Figure 2, different phosphorus source treatments can significantly affect the content of Al-P in soil at different stages. For lateritic red soil, the lower Al-P contents were recorded in APP2, APP3 and A3:M than MAP in whole cultured time. Moreover, there was no remarkable difference between MAP and APP1 and MAP at 15 and 30 days after fertilization. For latosol, there was no remarkable difference among APP1, APP3, A3:M and MAP in Al-P content while the lower content was recorded in APP2 than APP1, APP3, A3:M and MAP.

\section{Fe-P content in soil}

As shown in Figure 3, For lateritic red soil, higher Fe-P contents were recorded in APP1 and APP3 than MAP at 10, 15, 30 and 50 days after fertilization whilst the highest content was recorded in APP1 at 15, 30 and 50 days after the fertilization; For latosol, the highest Fe-P content was recorded in APP2 in whole cultured time while there was no remarkable difference between APP1 and MAP at 15, 30 and 50 days after the fertilization. 
Lateritic Red Soil

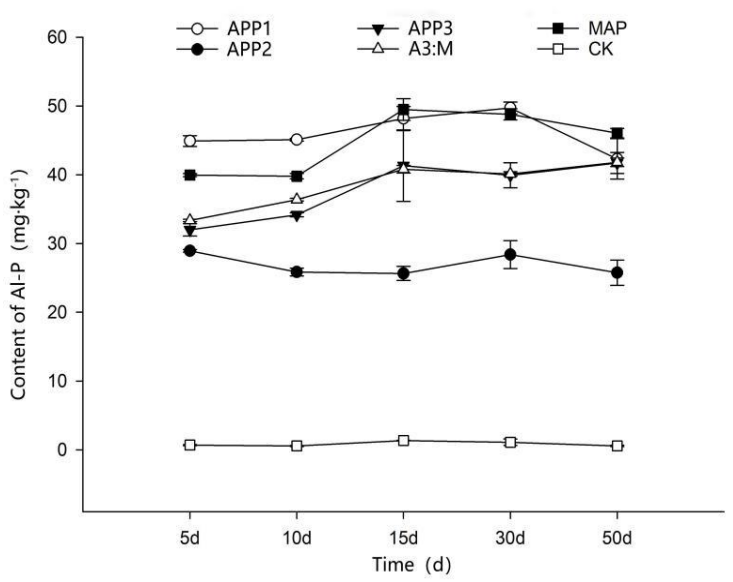

Latosol

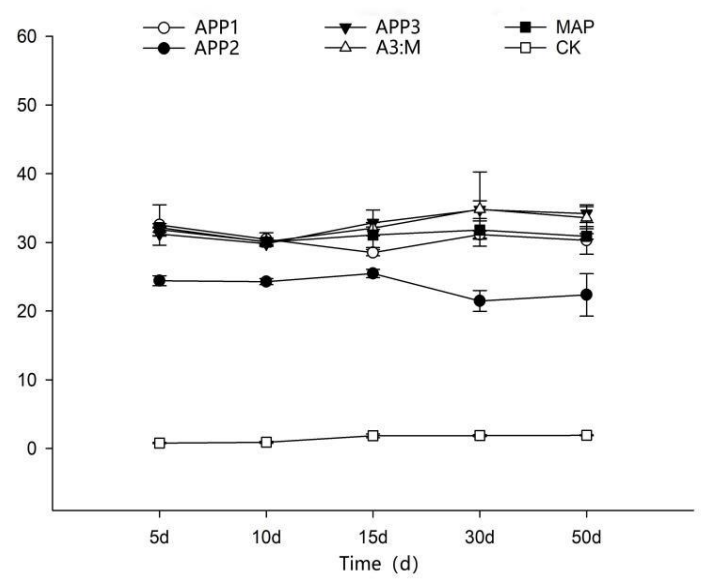

Figure 2. Dynamic changes of Al-P content in lateritic red soil and latosol under different phosphorus source treatments
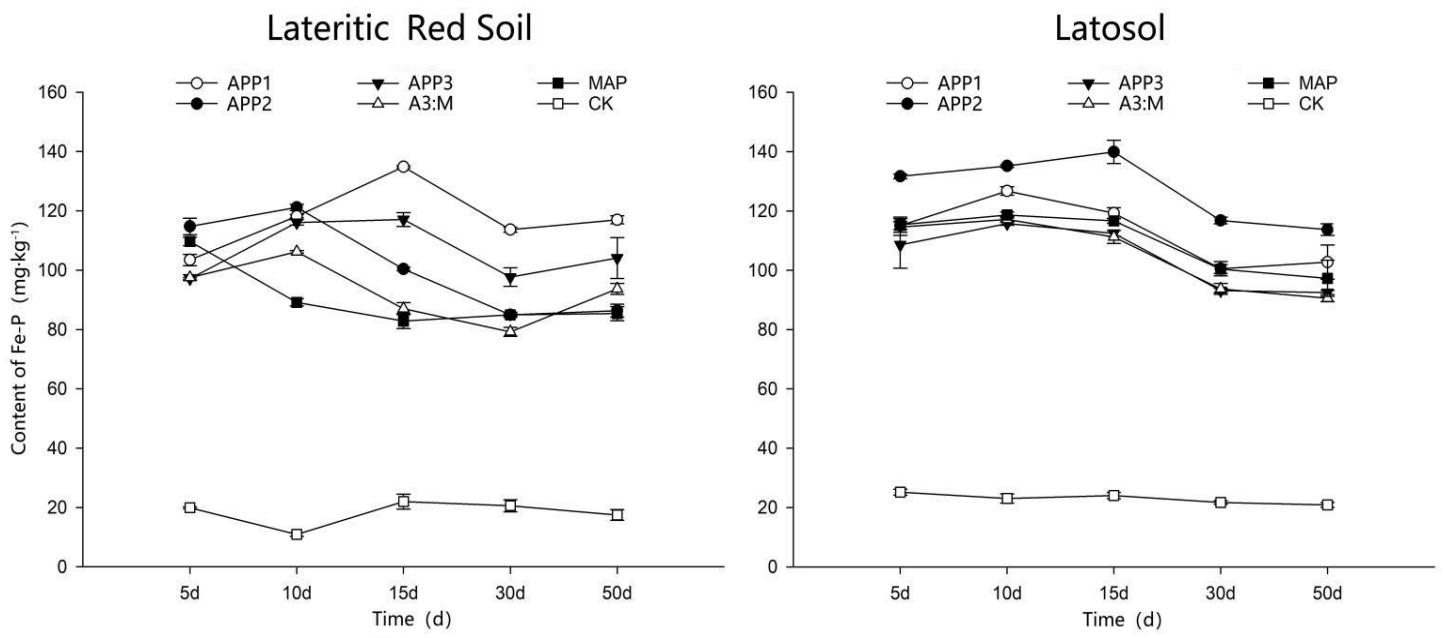

Figure 3. Dynamic changes of Fe-P content in lateritic red soil and latosol under different phosphorus source treatments

\section{O-P content in soil}

As shown in Figure 4, different phosphorus source treatments could significantly affect the content of O-P in soil. For lateritic red soil, the highest O-P content was recorded in APP2 in whole cultured time while there was no significant difference among APP1, APP3, A3:M and MAP in O-P content at 5, 15, 30 and 50 days after the fertilization; For latosol, the highest O-P content was also recorded in APP2 in whole cultured time while there was no significant difference among APP1, APP3, A3:M and MAP in O-P content at 15, 30 and 50 days after the fertilization.

\section{Ca-P content in soil}

As shown in Figure 5, no matter in latosol or in lateritic soil, no matter whether there was fertilization treatment or not, the Ca-P content of each treatment was low. For 
lateritic red soil, the Ca-P content in the soil could be significantly increased at 5 and 10 days after fertilization, but at 15 and 30 days, the Ca-P content of each fertilization treatment was not significantly higher than that of CK treatment. In addition, the content of Ca-P fluctuated in the range of 3-9 $\mathrm{mg}^{\mathrm{kg}} \mathrm{kg}^{-1}$. For latosol, the Ca-P content of fertilization treatment was significantly higher than that of CK treatment at 5 days, but with the extension of time, the Ca-P content of each treatment gradually stabilized in the range of $4-6 \mathrm{mg} \cdot \mathrm{kg}^{-1}$.
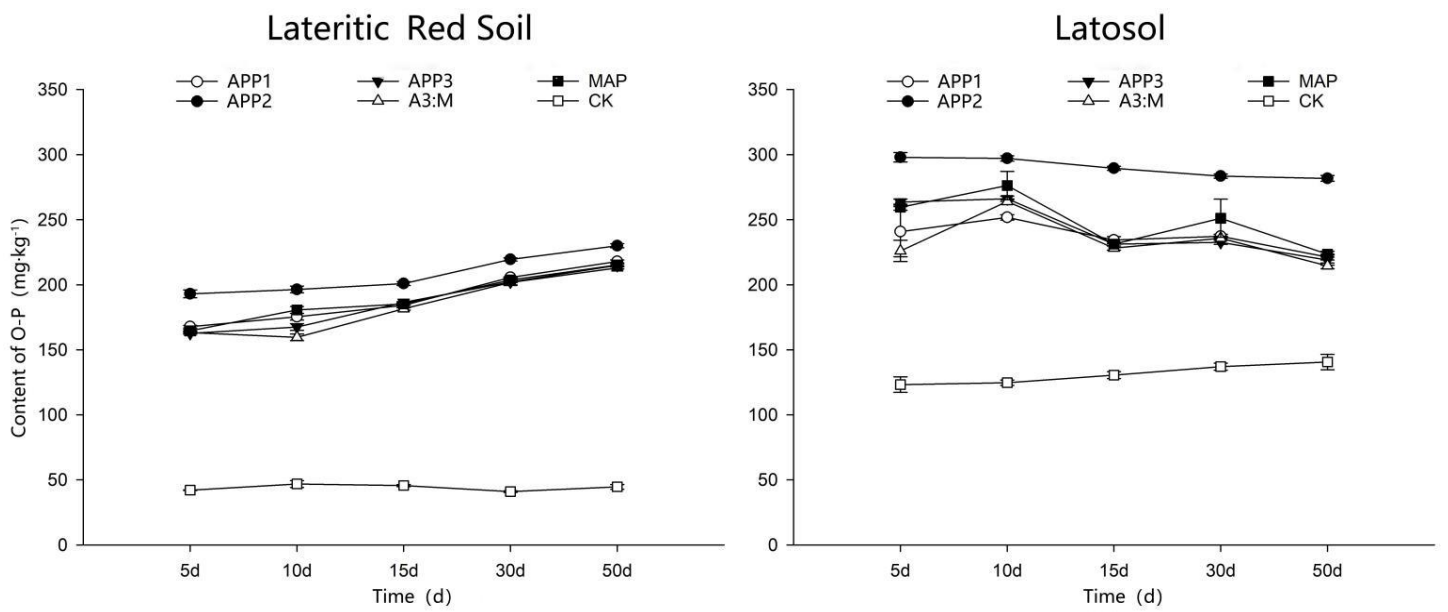

Figure 4. Dynamic changes of $O-P$ content in lateritic red soil and latosol under different phosphorus source treatments
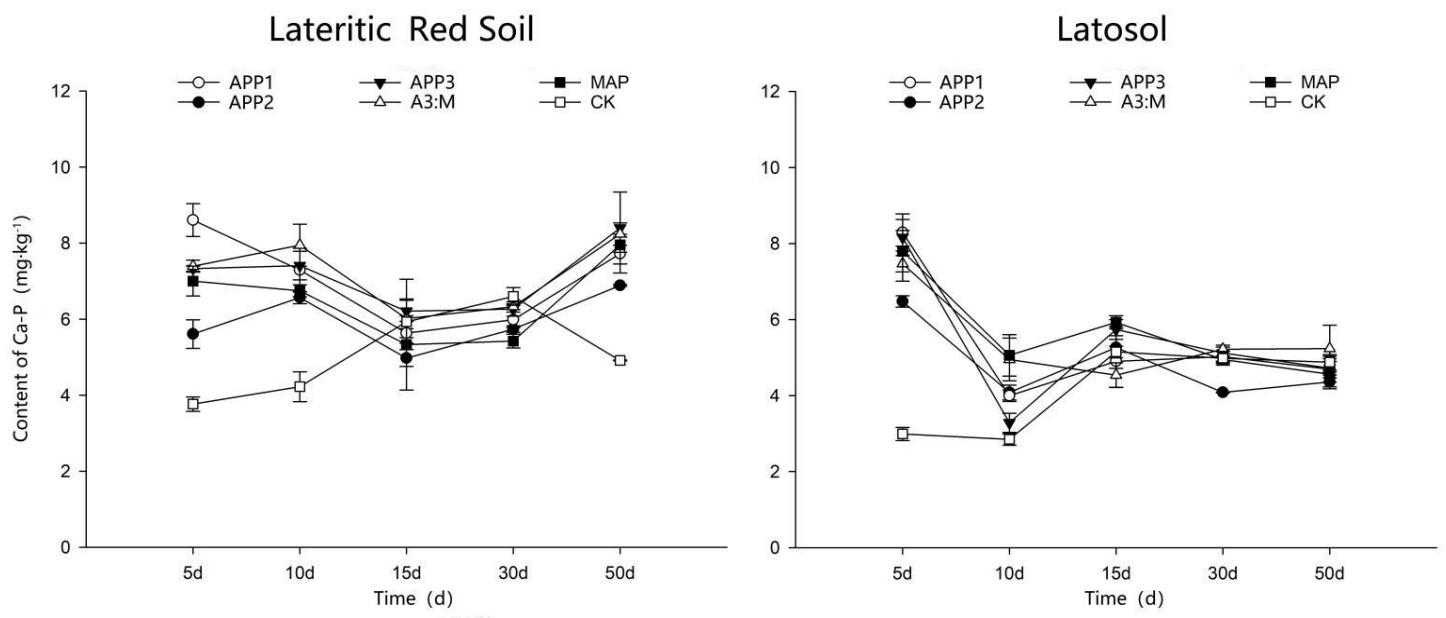

Figure 5. Dynamic changes of Ca-P content in lateritic red soil and latosol under different phosphorus source treatments

\section{Discussion}

The phosphorus content is an important index to determinate the soil fertility. Many studies have been conducted with the objective to improve soil phosphorus concentration. For example, the study of de Medeiros et al. (2019) found that application of green manure with rock phosphate was able to significantly increase soil phosphorus content. Present study revealed the effects of different degree of APP on the 
forms and availability of phosphorus in acidic soils. As far as available P content in soil was concerned, different phosphorus fertilizer treatments had different effects on available phosphorus content in latosol and lateritic red soil. For example, lower available P content was recorded in A3:M than MAP in lateritic red soil whilst in latosol, the available $\mathrm{P}$ content in soil increased significantly due to A3:M compared to MAP. The differences between two soil types might be attributed to the $\mathrm{P}$ fixation ability of soil because $\mathrm{P}$ fixation ability of different soils varies greatly, which also significantly affects the change of available P content in soils (Netzer et al., 2019; Shen et al., 2019). The study of Gao et al. (2019) showed that the application of ammonium polyphosphate in calcareous soil could significantly improve the available $\mathrm{P}$ and reduce the transformation from unstable P to recalcitrant P. In this study, we have come to a new conclusion: it was difficult for ammonium polyphosphate to show slow-release property in lateritic red soil, while in latosol, only APP3 and A3:M which were evenly distributed showed slow-release property. The new conclusions might be due to the different soil pH, which was also proposed by Wang et al. (2019) in her study. Subbarao and Ellis (1975) study showed that APP hydrolysis rate was faster in acid soil, which was not conducive to the accumulation of soil available phosphorus. The study of Hong et al. (2018) showed that the effects of biochar, fly ash and lime on phosphorus availability in acidic soils vary greatly, which also proves the effect of $\mathrm{pH}$ on the availability of phosphorus in acid soil. Do Nascimento et al. (2018) demonstrated that the application of granular monoammonium phosphate as based fertilizers could significantly affected the P mobility and behavior in soils. Koch et al. (2018) showed that phosphorus is the limiting nutrient element in the soil, and improving the utilization efficiency of phosphorus will help to improve the yield of crops. The study of Kang et al. (2018) showed that the application of liquid fertilizer was helpful to the absorption of nutrients and the yield of strawberry. Therefore, it also showed that liquid phosphorus fertilizer was beneficial to the utilization efficiency of phosphorus. In our study, in order to improve the content of available phosphorus in soil, APP1 is the most suitable phosphorus fertilizer to be applied in lateritic red soil while the application of APP3 combined with MAP can promote the increase of available phosphorus content in latosol. In addition, in the process of agricultural planting, if APP liquid phosphate fertilizer is applied, the content of available phosphorus in soil and the utilization efficiency of phosphate fertilizer will be improved.

For the transformation of different phosphorus sources in two soils, whether latosol or lateritic red soil, the inorganic phosphorus content in the soil could be expressed by $\mathrm{O}-\mathrm{P}>\mathrm{Fe}-\mathrm{P}>\mathrm{Al}-\mathrm{P}>\mathrm{Ca}-\mathrm{P}$ after applying phosphorus fertilizer (Table 4). The results showed that the total phosphorus content of the two soils were basically the same, but the biggest difference was that the O-P content of latosol was significantly higher than that of lateritic red soil, which was the reason why the available phosphorus in latosol was significantly lower than that of lateritic red soil. Therefore, two hypotheses can be drawn. The first one is that the application of phosphorus fertilizer in latosol is easier to convert Olsen-P into O-P form, and the increase of O-P may inhibit the content of Al-P. Second, O-P in lateritic red soil was more easily transformed into Olsen-P and Al-P forms by fertilization. Cheng et al. (2019) showed that high load agricultural planting will lead to the transformation of Al-P, Fe-P and Ca-P into O-P. Therefore, how to prevent the transformation of available phosphorus into unusable invalid phosphorus (O-P) will be the key to improve the utilization efficiency of phosphate fertilizer and alleviate the shortage of phosphate fertilizer resources. Besides, it can also help to 
improve the slow release of ammonium polyphosphate, so as to effectively reduce the times of fertilization to achieve the purpose of saving labor costs and ensuring the effect of fertilization.

Table 4. The content range of various forms of phosphorus in two soil types after fertilization treatment in 50 days

\begin{tabular}{c|c|c|c|c|c}
\hline Soil type & $\begin{array}{c}\text { Al-P } \\
\left(\mathbf{m g} \cdot \mathbf{k g}^{-\mathbf{1}}\right)\end{array}$ & $\begin{array}{c}\mathbf{F e}-\mathbf{P} \\
\left(\mathbf{m g} \cdot \mathbf{k g}^{-\mathbf{1}}\right)\end{array}$ & $\begin{array}{c}\mathbf{O}-\mathbf{P} \\
\left(\mathbf{m g} \cdot \mathbf{k g}^{-\mathbf{1}}\right)\end{array}$ & $\begin{array}{c}\mathbf{C a}-\mathbf{P} \\
\left(\mathbf{m g} \cdot \mathbf{k g}^{-\mathbf{1}}\right)\end{array}$ & $\begin{array}{c}\text { Olsen-P } \\
\left(\mathbf{m g} \cdot \mathbf{k g}^{-1}\right)\end{array}$ \\
\hline Lateritic red soil & $25-50$ & $80-140$ & $150-230$ & $3-9$ & $100-300$ \\
Latosol & $20-35$ & $80-140$ & $220-300$ & $3-9$ & $15-40$ \\
\hline
\end{tabular}

\section{Conclusion}

For lateritic red soil, the combination of APP3 and MAP could enhance the fixation of soil phosphorus and reduce the ability of improving soil available phosphorus, and the effect of APP1 alone was the best. For latosol, APP3 combined with MAP could significantly improve the release of soil available phosphorus, and had good slowrelease performance. Although the early effect was good, the slow-release performance of APP1 was poor, as time goes on, the effective phosphorus of APP1 was fixed by the soil faster than the release rate of effective phosphorus. In addition, in the two soils, the soil available phosphorus content of APP2 were low, and there was no obvious trend to improve the soil available phosphorus, which indicates that APP with too few low polymer cannot provide enough phosphorus for plants in the early stage, and the released phosphorus in the middle and later stage is easy to be fixed by the soil, which is not conducive to the accumulation of soil available phosphorus. Therefore, the effect of APP on the content of soil available phosphorus and the application effect were not necessarily better than MAP. In addition, although the content of inorganic phosphorus in the two soils were O-P > Fe-P > Al-P > Ca-P, the content of O-P in latosol was significantly higher than that in lateritic red soil, which was the main reason that the content of Olsen-P in latosol was significantly lower than that in lateritic red soil. Therefore, it is necessary to study the transformation relationship and conditions between O-P and Olsen-P, which will greatly reduce the fixation of available phosphorus in soil and improve the utilization rate of phosphorus fertilizer.

Acknowledgements. This study was supported by National Science and technology support program in rural areas during the 12th Five Year Plan (2013BAD05B04F05) and National key R \& D projects of the Ministry of science and technology (2016YFD0200404).

\section{REFERENCES}

[1] Chang, S. C., Jackson, M. L. (1957): Fractionation of soil phosphorus. - Soil Science 84: 133-144.

[2] Cheng, Z., Chen, Y., Gale, W. J., Zhang, F. (2019): inorganic phosphorus distribution in soil aggregates under different cropping patterns in Northwest China. - Journal of Soil Science and Plant Nutrition 19(1): 166-174.

[3] de Medeiros, E. V., Silva, A. O., Duda, G. P., Santos, U. J. D., de Souza Junior, A. J. (2019): The combination of Arachis pintoi green manure and natural phosphate improves 
maize growth, soil microbial community structure and enzymatic activities. - Plant \& Soil. DOI: 10.1007/s11104-018-3887-z.

[4] de Oliveira Araújo, É., Ferreira Dos Santos, E., Queiroz De Oliveira, G., Camacho, M. A., Mugnol Dresch, D. (2012): Nutritional efficiency of cowpea varieties in the absorption of phosphorus. - Agronomía Colombiana 30: 419-424.

[5] Do Nascimento, C. A. C., Pagliari, P. H., Faria, L. D. A., Vitti, G. C. (2018): Phosphorus mobility and behavior in soils treated with calcium, ammonium, and magnesium phosphates. - Soil Science Society of America Journal 82: 622-631.

[6] Gao, Y., Wang, X., Shah, J. A., Chu, G. (2019): Polyphosphate fertilizers increased maize (Zea mays, L.) P, Fe, Zn, and Mn uptake by decreasing P fixation and mobilizing microelements in calcareous soil. - Journal of Soils and Sediments 20: 1-11.

[7] Giles, C. D., Cade-Menun, B. J., Liu, C. W., Hill, J. E. (2015): The short-term transport and transformation of phosphorus species in a saturated soil following poultry manure amendment and leaching. - Geoderma 257: 134-141.

[8] Hong, C., Su, Y., Lu, S. (2018): Phosphorus availability changes in acidic soils amended with biochar, fly ash, and lime determined by diffusive gradients in thin films (DGT) technique. - Environmental Science and Pollution Research 25: 30547-30556.

[9] Kang, R., Niu, J., Chen, Z., Zhang, J. (2018): Effects of different water-soluble fertilizers on yield and quality of strawberry under integrated application of water and fertilizer. Asian Agricultural Research 10: 63-65+70.

[10] Koch, M., Kruse, J., Eichler-Löbermann, B., Zimmer, D., Siebers, N. (2018): Phosphorus stocks and speciation in soil profiles of a long-term fertilizer experiment: evidence from sequential fractionation, P K-edge XANES, and 31P NMR spectroscopy. - Geofisica Internacional 316: 115-126.

[11] Lu, R. (1999): Soil Agrochemical Analysis Method. - China Agricultural Science and Technology Press, Beijing.

[12] Martin, A. E., Reeve, R. (1955): A rapid manometric method for determining soil carbonate. - Soil Science 79: 187-198.

[13] Netzer, F., Turnbull, T., Mult, S., Alfarraj, S., Albasher, G., Herschbach, C., Adams, M., Rennenberg, H. (2019): Mineral nutrition of sub-alpine Australian vegetation under nutrient deficiency depends on lifeform. - Environmental and Experimental Botany 160: 92-100.

[14] Rosen, C. J., Kelling, K. A., Stark, J. C., Porter, G. A. (2014): Optimizing phosphorus fertilizer management in potato production. - American Journal of Potato Research 91: $145-160$.

[15] Shaw, K. (1959): Determination of organic carbon in soil and plant material. - European Journal of Soil Science 10: 316-326.

[16] Sheil, T. S., Wall, D. P., Culleton, N., Murphy, J., Grant, J., Lalor, S. T. J. (2016): Longterm effects of phosphorus fertilizer on soil test phosphorus, phosphorus uptake and yield of perennial ryegrass. - Journal of Agricultural Science 154: 1068-1081.

[17] Shen, Y., Duan, Y., McLaughlin, N., Huang, S., Guo, D., Xu, M. (2019): Phosphorus desorption from calcareous soils with different initial Olsen-P levels and relation to phosphate fractions. - Journal of Soils and Sediments 19: 2997-3007.

[18] Singh, S. K., Reddy, V. R., Fleisher, D. H., Timlin, D. J. (2014): Growth, nutrient dynamics, and efficiency responses to carbon dioxide and phosphorus nutrition in soybean. - Journal of Plant Interactions 9: 838-849.

[19] Smith, S. E., Jakobsen, I., Gronlund, M., Smith, F. A. (2011): Roles of arbuscular mycorrhizas in plant phosphorus nutrition: interactions between pathways of phosphorus uptake in arbuscular mycorrhizal roots have important implications for understanding and manipulating plant phosphorus acquisition. - Plant Physiology 156: 1050-1057.

[20] Subbarao, Y. V., Ellis, R. (1975): Reaction products of polyphosphates and orthophosphates with soils and influence on uptake of phosphorus by plants. - Soil Science Society of America Journal 39: 1085. 
[21] Summerhays, J. S., Jolley, V. D., Hill, M. W., Hopkins, B. G. (2017): Enhanced phosphorus fertilizers (Carbond $\mathrm{P}(\mathrm{R})$ and Avail $(\mathrm{R})$ ) supplied to maize in hydroponics. Journal of Plant Nutrition 40: 2889-2897.

[22] Wang, X., Gao, Y., Hu, B., Chu, G. (2019): Comparison of the hydrolysis characteristics of three polyphosphates and their effects on soil $\mathrm{P}$ and micronutrient availability. - Soil Use and Management. https://doi.org/10.1111/sum.12526.

[23] Yang, J., Kong, X., Xu, D., Xie, W., Wang, X. (2019): Evolution of the polydispersity of ammonium polyphosphate in a reactive extrusion process: polycondensation mechanism and kinetics. - Chemical Engineering Journal 359: 1453-1462.

\section{APPENDIX}

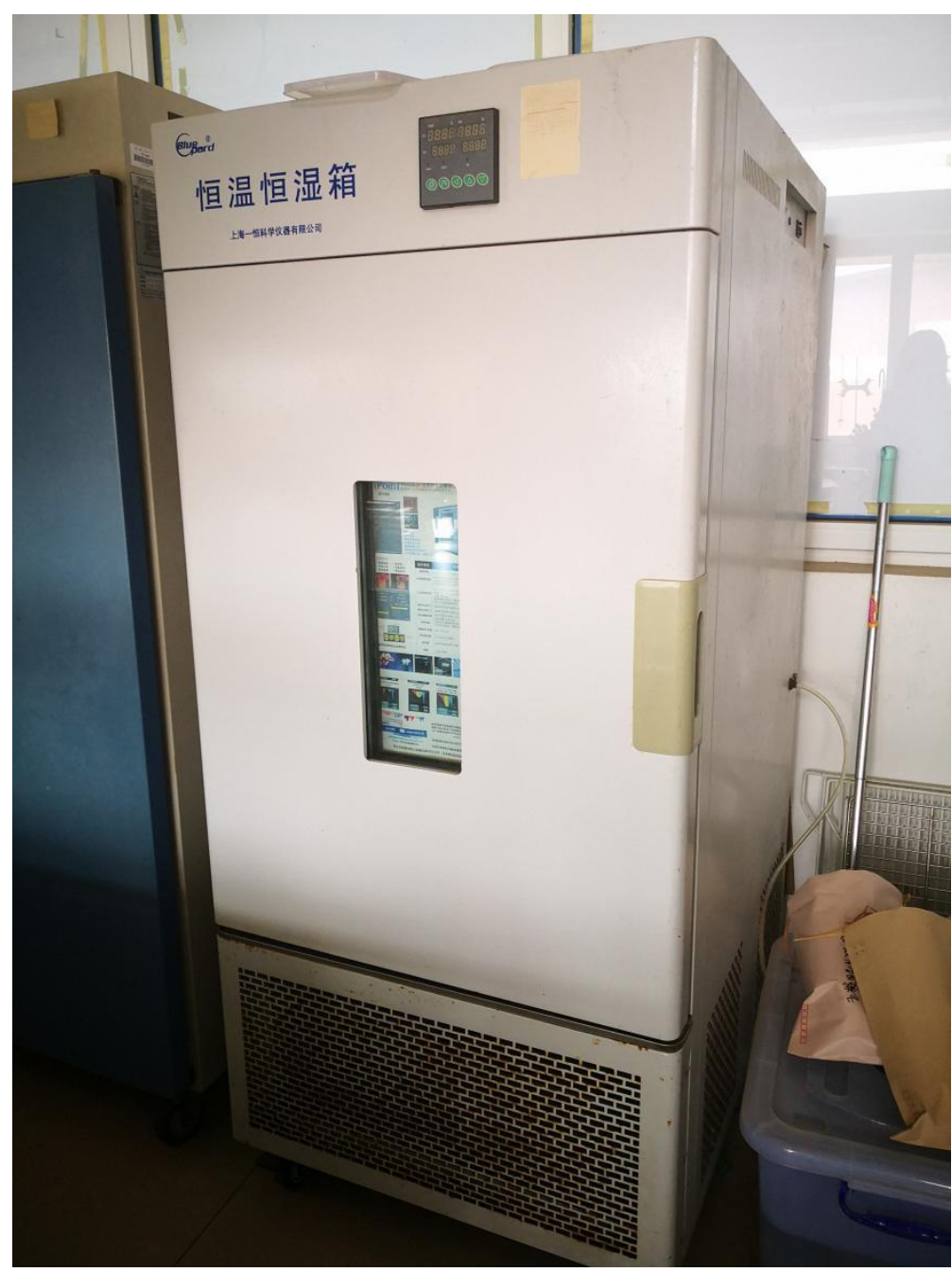

Appendix 1. Equipment 